\title{
O USO DE IMAGENS E INFORMAÇÕES PESSOAIS DA CRIANÇA E DO ADOLESCENTE PARA A PROMOÇÃO DE ADOÇÕES NECESSÁRIAS
}

Laísa Fernanda Campidelli ${ }^{1}$

\section{Resumo:}

Considerando o princípio da proteção integral do menor, objetiva-se, com esse estudo, analisar o direito à imagem da criança e do adolescente e a sua utilização em fotos e vídeos na internet para possibilitar mais chances de adoções. Para tanto, procede-se à pesquisa bibliográfica, à análise do mecanismo Busca Ativa, através das redes sociais e de campanhas, além de dados constantes no $\mathrm{CNJ}$, desenvolvendo-se a pesquisa pelo método dedutivo. Conclui-se que, apesar do caráter excepcional, o uso de imagens e informações pessoais para concretização de adoções necessárias se mostra eficaz e proporciona a convivência familiar, fundamental para o desenvolvimento sadio.

\section{Palavras-chave:}

Adoção tardia. Adoção Especial. Convivência Familiar. Busca Ativa. Campanhas.

\section{THE USE OF IMAGES AND PERSONAL INFORMATION FOR CHILDREN AND ADOLESCENTS FOR THE PROMOTION OF NECESSARY ADOPTIONS}

\begin{abstract}
:
Considering the principle of integral protection of minors, this study aims to analyze the image right of children and adolescents and its use in photos and videos on the Internet to enable more chances of adoptions. Therefore, we proceed to the bibliographic research, to the analysis of the Active Search mechanism through the social networks and campaigns, besides CNJ's constant data, being the research developed by the deductive method. It is concluded that, despite the exceptional nature, the use of images and personal information to achieve the necessary adoptions is effective and provides family coexistence, fundamental for healthy development.
\end{abstract}

\section{Keywords:}

Late adoption. Special Adoption. Family living. Active Search. Campaigns.

\section{INTRODUÇÃO}

A Constituição Federal de 1988, no art. 227, exprime ser dever da família, da sociedade e do Estado assegurar à criança, ao adolescente e ao jovem, com absoluta prioridade, vários direitos que lhe garantam a vida com dignidade. O Estatuto da Criança e do Adolescente

\footnotetext{
${ }^{1}$ Mestranda em Direito pela Universidade Estadual do Norte do Paraná (2018-2019). Graduada em Direito pela Universidade Estadual do Norte do Paraná (2017). Bolsista CAPES. Integrante do grupo de pesquisa GP CERTOS. E-mail:laisacampidelli@gmail.com.
} 
(ECA), o Código Civil e a Lei 12.010/09 corroboram para assegurar que todo menor tenha sua proteção integral e crescimento sadio assegurados.

Muitas crianças e adolescentes, entretanto, não possuem todos os direitos que lhes garantiriam viver dignamente assegurados. Quando as famílias biológicas não possuem condições de cuidar de seus filhos, pelos mais diversos fatores, os direitos deles são retirados temporariamente até que o lar seja reestruturado e possa proporcionar-lhes o crescimento sadio. Ocorre que esse processo é moroso e muitas vezes ineficaz. Além disso, somente quando foram exauridas todas as tentativas com relação à família biológica e extensa - conforme exigência da Lei 12.010 - é que ocorre a destituição do poder familiar.

Em todo esse processo, a criança e o adolescente ficam afastados do convívio familiar, às vezes por anos, causando inestimáveis danos, pois a instituição não é capaz de fornecer afeto individualmente. Porém, esse não é o maior dos entraves. Em virtude da destituição tardia do poder familiar, encontrar pretendentes à adoção é muito mais dificultoso. Além disso, condições físicas das crianças e adolescentes, como doenças e deficiências, somam outro obstáculo à concretização dessas adoções.

Conforme Conselho Nacional de Justiça $(\mathrm{CNJ})^{2}$, o número de candidatos à adoção é cinco vezes maior que o de crianças e adolescentes inscritos no Cadastro Nacional da Adoção (CNA), entretanto, esses pretendentes possuem perfis que não se encaixam aos dos menores disponíveis. Todavia, essas adoções são necessárias para a garantia da proteção integral dessas crianças e adolescentes, devendo o Estado buscar mecanismos que possam mudar essa realidade. Para proporcionar essa garantia, atualmente, algumas comarcas utilizamse do sistema Busca Ativa, de campanhas e da internet para procurar candidatos interessados em adotar esses menores e promover a ampliação do perfil, vencendo os preconceitos e obstáculos. Contudo, a mencionada busca - de caráter excepcional - faz uso de imagens e informações pessoais das crianças e adolescentes, o que pode ser questionável, pois como a internet é aberta a todos, não se pode saber, a priori, o que pessoas mal-intencionadas poderiam fazer com essas imagens e informações.

\footnotetext{
${ }^{2}$ Conformes relatórios do dia 10 de abril de 2019.
} 
Dessa forma, busca-se analisar, por meio do presente estudo, o direito à imagem da criança e do adolescente, contrapondo-o ao direito à convivência familiar e, por fím, trazer exemplos fáticos da narrada situação, com a finalidade de garantir o melhor interesse do menor.

A pesquisa é desenvolvida pelo método dedutivo, utilizando-se da pesquisa bibliográfica, da análise do mecanismo Busca Ativa, através das redes sociais e de campanhas, e de dados constantes no Conselho Nacional de Justiça (CNJ).

\section{O DIREITO À IMAGEM DA CRIANÇA E DO ADOLESCENTE}

O direito à imagem constitui importante direito da personalidade, trazido pela Constituição Federal de $1988^{3}$. Além disso, face a crianças e adolescentes, a cautela com relação a esse direito é ainda maior, sendo implementada pelo Estatuto da Criança e do Adolescente (ECA) em seu Art. 17, o qual menciona que "o direito ao respeito consiste na inviolabilidade da integridade física, psíquica e moral da criança e do adolescente, abrangendo a preservação da imagem, da identidade, da autonomia, dos valores, ideias e crenças, dos espaços e objetos pessoais". O Código Civil no Art. $20^{4}$ também assegura o direito à imagem, esclarecendo que em alguns casos a exposição poderá ser proibida.

Conforme explica Bittar (2015, p. 153) o direito à imagem:

Consiste no direito que a pessoa tem sobre a sua forma plástica e respectivos componentes distintos (rosto, olhos, perfil, busto) que a individualizam no seio da coletividade. Incide, pois, sobre a conformação física da pessoa, compreendendo esse direito um conjunto de caracteres que a identifica no meio social. Por outras palavras, é o vínculo que une a pessoa à sua expressão externa, tomada no conjunto, ou em partes significativas (como a boca, os olhos, as pernas, enquanto individualizadoras da pessoa).

\footnotetext{
${ }^{3}$ Constituição Federal de 1988

Art. $5^{\circ}$ (...) X - são invioláveis a intimidade, a vida privada, a honra e a imagem das pessoas, assegurado o direito a indenização pelo dano material ou moral decorrente de sua violação;

XXVIII - são assegurados, nos termos da lei:

a) a proteção às participações individuais em obras coletivas e à reprodução da imagem e voz humanas, inclusive nas atividades desportivas;

${ }^{4}$ Código Civil - Art. 20. Salvo se autorizadas, ou se necessárias à administração da justiça ou à manutenção da ordem pública, a divulgação de escritos, a transmissão da palavra, ou a publicação, a exposição ou a utilização da imagem de uma pessoa poderão ser proibidas, a seu requerimento e sem prejuízo da indenização que couber, se lhe atingirem a honra, a boa fama ou a respeitabilidade, ou se se destinarem a fins comerciais.
} 
O direito à imagem baseia-se, como os demais direitos dessa ordem, no respeito à personalidade humana. Podendo ser considerado como a "defesa da figura humana em si". Constituindo-se ato ilícito o uso não consentido. (BITTAR, 2015, p. 155).

Ocorre que na presente situação, a criança e o adolescente ainda não têm condições de decidir sobre o uso de sua imagem e de suas informações, cabendo ao Estado intervir por elas, uma vez que estão sob sua tutela. A decisão engloba aspectos que ainda não podem ser descritos.

O projeto "Esperando Por Você", do Tribunal de Justiça do Espirito Santo, por meio do YouTube, expõe vídeos em que as crianças e adolescentes institucionalizados, e sem pretendentes à adoção, aparecem procurando candidatos a pais. Os vídeos são totalmente abertos ao público, porém só podem se candidatar à adoção pessoas já habilitadas no Cadastro Nacional de Adoção (CNA) (TRIBUNAL DE JUSTIÇA ESPÍRITO SANTO, 2019, online). Semelhante mecanismo é utilizado pela Comissão Estadual Judiciária de Adoção de Pernambuco (CEJA-PE), por meio das redes sociais facebook e instagram, e também de site próprio, através dos quais divulgam-se fotos e vídeos das crianças e dos adolescentes com as respectivas descrições, buscando por candidatos a adotá-las ou apadrinhá-las (PODER JUDICIÁRIO DE PERNAMBUCO, 2019, online). O sistema é totalmente aberto ao público.

Todavia, por melhor que sejam as intenções, quando se expõe imagens de crianças e adolescentes na internet criam-se riscos que precisam ser elencados, pois poderão desencadear consequências futuras. Os menores que estão em instituições de acolhimento são mais vulneráveis do que outras crianças, e é constante sentirem-se diferentes de seus pares que têm pais, além de apresentar carência de afeto e atenção. Tal situação poderia ser potencializada caso a busca pela internet fosse frustrada e, por exemplo, o vídeo caísse nas mãos de um colega da escola ou alguém mal-intencionado, passando a servir como mote para ataques depreciativos que evidenciassem, entre outras coisas, que a criança ou adolescente fora abandonado pela família biológica ou que ele ainda não encontrou nenhum candidato para adotá-lo, mesmo depois de milhares de visualizações em seu vídeo. Diante disso, é necessário analisar o psicológico da criança e do adolescente institucionalizado e protegê-lo contra os males que podem causar danos.

Nesse sentido explica Bittar (2015, p. 112) sobre a proteção aos direitos da personalidade: 
O objetivo fundamental dessa proteção é assegurar a cada qual a respectiva Integridade (...) Com essa proteção, evita-se que sejam esses bens oferecidos a conhecimento, ou a fruição de terceiros, ou mesmo submetidos a ações deletérias ou depreciativas, enfim, a resultados não desejados pela pessoa e, portanto, contrários à ordem jurídica. Representam esses direitos, sob esse prisma, verdadeiras muralhas de proteção à sua integridade antepostas pelo direito como defesa da pessoa diante de invasões de qualquer outro componente da coletividade.

A proteção é essencial, pois existem riscos com a exposição a qualquer espectador. Como mencionado, é comum que as crianças e adolescentes sejam carentes de apego e amor, e quando seus rostos são mostrados, identificando-os - algumas vezes expondo de forma evidente o anseio por afeto - pessoas mal-intencionadas podem se aproveitar dessa maior vulnerabilidade para aproximar-se, já que, por exemplo, muitos dos institucionalizados são adolescentes que têm atividades fora da instituição.

Nesse sentido destaca-se a vulnerabilidade da criança;

Em causa está a prevenção de lesões irreversíveis ao desenvolvimento da personalidade dos menores, à sua adequada socialização e à sua capacidade de autodeterminação, nos planos físico, intelectual, moral, emocional e relacional, às quais os mesmos, pela sua maior sugestionabilidade $\mathrm{e}$ impressionabilidade, são particularmente vulneráveis. (CANOTILHO; MACHADO, 203, p. 59).

Com relação à exposição de imagens de crianças, ainda, Cordeiro (2004, p. 194) esclarece que a imagem de uma pessoa é um bem de personalidade fortemente objetivado e, por essa razão, o destino dado à imagem é, de certa maneira, um tratamento dado à própria pessoa. Assim, é importante considerar que, mesmo tendo uma boa finalidade para a promoção da adoção, as imagens e informações dos menores poderão ser copiadas e utilizadas para outros fins, por pessoas não autorizadas. O legislador, atento para as mudanças da sociedade, desejou oferecer ampla proteção. Conforme dispõe Bittar (2015, p. 108):

(...) deseja o legislador conferir ampla proteção à pessoa humana em face dos ataques comuns e quotidianos, contra a honra (subjetiva e objetiva), por meio do uso do nome em publicações ou exposições, hoje comuns e disseminadas com o uso irrestrito da internet para efeitos denegritórios da integridade alheia. É de estremecer a abrangência dessa disposição, uma vez que alcança toda e qualquer forma de manifestação pública, escrita ou oral (teatro, cinema, palestra, aula, artigo de jornal, artigo de revista, livro, crítica pública 
...), em que o desprezo se manifeste com o emprego do nome da pessoa titular do direito ofendido. Protege-se, aqui, não somente o nome, mas sobretudo a honra, também categorizada entre os direitos da personalidade de caráter moral.

Apesar dos riscos que a exposição de imagens e informações pessoais das crianças e adolescentes podem gerar, ela poderá proporcionar uma família àqueles que tanto a desejam, devendo apenas ser considerada a hipótese de os vídeos serem divulgados em sistemas mais restritos, como o A.DOT que é um aplicativo que conecta menores aptos à adoção com pretendentes habilitados no Cadastro Nacional de Adoção (ADOT, 2019, online). Os vídeos e imagens só podem ser visualizados por candidatos já habilitados, possibilitando a mudança e ampliação dos perfis.

A psicóloga Eliana Knopman (2014, p. 238), a qual realizou pesquisa sobre a Busca Ativa, expõe que a internet é um recurso precioso em virtude do seu alcance, não devendo ser rejeitada pelo do mau uso que as pessoas mal-intencionadas possam fazer dela. A autora destaca que para aqueles de má-fé será aplicada o rigor da Lei, mas que isso não impede a construção de uma nova cultura da adoção no Brasil. Caberá, portanto, análise por parte do magistrado sobre o uso da imagem e de informações pessoais da criança e o do adolescente no caso concreto. Nesse sentido, Bittar (2015, p. 106- 107) cita que a avaliação do caso concreto e o perfil do perigo produzido é que levam o juiz à tomada da postura adequada para sanar e debelar a iminente ou atual ameaça ao direito da personalidade afetado.

Dessa forma, observa-se que, apesar dos riscos que a exposição na internet traz, o aumento da probabilidade de se conseguir uma família pode ser mais valioso, demonstrandose que, face à importância da família para o desenvolvimento de toda criança e adolescente, sua imagem e informações pessoais poderão ser utilizadas, desde que com cautela e em seu benefício, sempre tendo em vista o melhor interesse no menor.

\section{O DIREITO FUNDAMENTAL À CONVIVÊNCIA FAMILIAR}

O direito Fundamental à convivência familiar está expresso no Art. $227^{5}$ da Constituição Federal. A prioridade é ele seja garantido na família biológica ou na família

\footnotetext{
${ }^{5}$ Constituição Federal de 1988
} 
extensa, e somente em caráter de exceção em famílias substitutas, conforme Art. 19 do Estatuto da Criança e do Adolescente (ECA). O ambiente deverá garantir o desenvolvimento integral. Ademais, os menores gozam de todos os direitos fundamentais inerentes à pessoa humana, conforme Art. $3^{\text {o }}$, também do ECA.

Com a Lei 12.010, evidenciou-se ainda mais a opção pela família biológica que, comumente, torna-se prejudicial para as crianças, pois crescem na instituição e depois não regressam à família biológica, ou não conseguem pretendentes aptos a adotá-las. Nessa perspectiva, Dias (2017) expõe sobre as expectativas com relação ao retorno ao lar:

O tempo em que ficam institucionalizados deve ser, no máximo de dois anos (ECA $19, \S 2^{\circ}$ ), porém, sempre é superior. Durante esse período, ninguém tem acesso a eles. Ficam na expectativa de serem resgatados pelos pais. Não são. Depois têm a esperança de que algum parente os queira. Não querem. Então começa a esmaecer o sonho de ter um lar. A cada ano que passa, diminuem a possibilidade de serem adotados (DIAS, 2017, p. 115).

A questão do tempo envolvendo os processos com crianças e adolescentes institucionalizados foi tratada pelo Conselho Nacional de Justiça (CNJ), na análise sobre os impactos da atuação do poder judiciário nesses processos, resultando na recomendação de que se reforçasse a supremacia do interesse da criança por meio da edição de normas principiológicas claras, seja através da modificação do ECA ou da edição de normas infralegais pelo Poder Judiciário, que tratem das situações de conflito e do problema do tempo (CONSELHO NACIONAL DE JUSTIÇA, 2015, p. 115). Porém, a edição de novas normas e recomendações não conserta o passado, restando as crianças e adolescentes vítimas da demora do judiciário e que tiveram e têm seu direito a convivência familiar suprimido.

A convivência familiar é essencial ao crescimento sadio de toda criança e todo adolescente. A instituição, por melhor que ela seja, não pode proporcionar o mesmo que uma

Art. 227 É dever da família, da sociedade e do Estado assegurar à criança, ao adolescente e ao jovem, com absoluta prioridade, o direito à vida, à saúde, à alimentação, à educação, ao lazer, à profissionalização, à cultura, à dignidade, ao respeito, à liberdade e à convivência familiar e comunitária, além de colocá-los a salvo de toda forma de negligência, discriminação, exploração, violência, crueldade e opressão.

${ }^{6}$ Estatuto da Criança e do Adolescente (ECA)

Art. $3^{\circ} \mathrm{A}$ criança e o adolescente gozam de todos os direitos fundamentais inerentes à pessoa humana, sem prejuízo da proteção integral de que trata esta Lei, assegurando-se-lhes, por lei ou por outros meios, todas as oportunidades e facilidades, a fim de lhes facultar o desenvolvimento físico, mental, moral, espiritual e social, em condições de liberdade e de dignidade. 
família. Mello (2003, p. 20) destaca que crianças e adolescentes privados da convivência familiar podem ter dificuldade em formar a própria identidade, sensação de diferença com relação à maioria de seus pares que têm pais, sentimentos de inferioridade, rejeição e baixa autoestima. Situação que prejudica seu presente e traz consequências e danos psicológicos para o seu futuro.

Diante da impossibilidade da família biológica, explica o psicólogo Freire (1994, p.7), a adoção é a única medida protetiva que cumpre com todas as funções que caracterizam uma família, pois permite refazer os vínculos da relação filial. A família é capaz de fortalecer o sentimento de autoestima, chave para o processo de uma personalidade sadia e construtiva.

Cuneo (2012, p. 416) desenvolveu um estudo no qual destaca os problemas gerados pela ausência familiar por longos períodos:

(...) a institucionalização prolongada impede a ocorrência de condições favoráveis ao sadio desenvolvimento da criança por conta da submissão a rotinas rígidas, do convívio restrito às mesmas pessoas, da precariedade de atenção individualizada e da falta de vida em família sem a oportunidade de trocas afetivas emocionalmente significativas. A descontinuidade dos vínculos iniciais e a ausência de um referencial cognitivo contribuem para a formação insegura dos padrões de apego, o que pode levar a prejuízos de ordem somática, emocional, intelectual e social. Marcas profundas e dolorosas geralmente afetam a criança institucionalizada por longo período e, se não adequadamente elaboradas, poderão se refletir na adultez, com efeitos perniciosos na formação do desenvolvimento do indivíduo.

Conforme dados do Cadastro Nacional da Adoção $^{7}$ (CNA), existem 45.898 pretendentes aptos à adoção e 9.475 crianças e adolescentes disponíveis para tal fim. Entretanto, por mais que existam muito mais candidatos do que menores, o perfil que os inscritos desejam é diferente do perfil das crianças e adolescentes aptos. Esses menores permanecem nas instituições de acolhimento até que apareça algum interessado em adotá-los, do contrário, devem deixá-las após completarem 18 anos.

Dessa forma, crianças mais velhas, com deficiência, com doenças não tratáveis, em grupos de irmãos e crianças negras são constantemente rejeitadas pelos candidatos à adoção. Essas são as denominadas adoções necessárias, as quais exigem que todos os

\footnotetext{
${ }^{7}$ Conformes relatórios do dia 10 de abril de 2019.
} 
envolvidos nos processos de adoção empenhem mecanismos além do Cadastro Nacional da Adoção para vencer os estigmas e preconceitos que as envolve. Explica Knopman (2014, p. 232) que manter essas crianças e adolescentes esperando é uma inobservância da proteção integral:

\begin{abstract}
A falta de ações efetivas, o abrigamento, hoje renomado como acolhimento institucional previsto no ordenamento jurídico como medida de proteção de caráter excepcional e temporário, aplicável nas hipóteses de necessário afastamento da família, acabou se revelando uma forma grave e oficial de violação do direito à convivência familiar e comunitária. Crianças acolhidas em tenra idade se tornaram adolescentes em institucionalizações crônicas, motivadas, na maioria das vezes, pela mera inobservância da proteção integral prevista na lei e muitas vezes perpetuadas pela inércia, pela acomodação e por uma cultura de institucionalização (...) ( KNOPMAN, 2014, p. 232).
\end{abstract}

Deixar essas crianças e adolescentes esperando por candidatos que talvez nunca cheguem é uma violação a sua própria dignidade, pois, como se viu, a ausência familiar causa danos. O Estado erra, portanto, ao acreditar que ao manter um menor em uma instituição de acolhimento por anos, sem convivência familiar, estaria garantindo seus direitos, visto que tal quadro pode afetar o psicológico do menor, prejudicadando-o após esse longo período de sofrimento.

As adoções necessárias são possíveis, desde que exista uma mudança na cultura que envolve a adoção em si. Diante disso, mister se faz o estabelecimento de uma política que incorpore o incentivo às adoções necessárias, seja por campanhas conscientes de mobilização e esclarecimento seja com subsídios financeiros, executadas com urgência (SCHREINER, 2004, p.22).

É por essa razão que depois de exaurirem as buscas por candidatos compatíveis no CNA, muitas comarcas estão se utilizando de novos recursos para a busca de pretendentes. Dentre esses mecanismos alternativos, estão a Busca Ativa e o uso de campanhas, ambos feitos pela internet, principalmente através das mídias sociais, as quais fazem uso das próprias crianças e adolescentes sem candidatos à adoção.

Buscando a construção do direito baseada não apenas em normas programáticas, mas em mecanismos efetivos de asseguração de direitos fundamentais, o 
presente estudo prosseguirá para a análise desses dois instrumentos como facilitadores de adoções necessárias, avaliando se preservam o melhor interesse do menor em questão.

\section{BUSCA ATIVA E CAMPANHAS}

A Busca Ativa é um dos mecanismos que vem sendo utilizado por várias comarcas para que menores que não possuem pretendentes no CNA encontrem pais. Esse sistema consiste na inversão da forma como se procuram pais para uma criança, partindo das especificidades dela e de quem a aceita tal como é, ou seja, a partir de sua descrição e de sua imagem.

Com o tempo, os adotantes frequentemente percebem que a criança idealizada não existe. Inclusive na própria filiação biológica, o filho não é igual à idealização. Por essa razão, existe a possibilidade de os pretendentes perceberem que há muitas crianças precisando de pais e que essas têm potencial para serem seus filhos. Nesse sentido, surge a Busca Ativa:

[...] a busca ativa é o auxílio legítimo e constitucionalmente autorizado prestado pela sociedade civil ao Estado na busca e localização de habilitados à adoção para crianças e adolescentes fora do perfil mais pretendidos por aqueles, quais sejam, maiores de 5 anos, grupos de irmãos inseparáveis, crianças e adolescentes com deficiências físicas e/ou mentais (PORTAL DA ADOÇÃO, 2019, online).

Por anos permaneceu a ideia de que as crianças e os adolescentes deveriam ficar totalmente ocultos pelas instituições, sendo proibida, em alguns casos, a visitação de pessoas com interesse em adotar. Entretanto, Knopman (2014, p. 234) explica que na comarca de Teresópolis a abertura das instituições para que as pessoas conheçam os menores possibilitou muitas adoções. Nesse sentido:

A população tradicionalmente preterida ganhava existência, tornava-se real, tornava-se uma possibilidade, e desejável, e foram muitas as adoções viabilizadas por encontros espontâneos, onde a simpatia surgiu naturalmente, se estreitou em contatos e visitas, e transformou-se em afeto genuíno. Foi assim que as irmãs negras $\mathrm{Y}, 8$ anos, I, 7 anos e K, 6 anos, conheceram seus pais.

A psicóloga Luchi (2014, p. 655) explica que "a adoção de crianças maiores pressupõe um encontro de história, da personalidade e das necessidades de uma criança com a 
história, as expectativas, a personalidade e a capacidade daqueles que desejam acolhê-la como filho". Dessa forma, as adoções necessárias são favorecidas quando as crianças e adolescentes podem ser vistos, seja ao vivo, na própria instituição, ou por meio da internet, quando ainda não se encontrou pretendentes de todas as outras formas. Os institucionalizados contam suas histórias, expectativas, o anseio por um lar, o que leva os pretendentes a pais, em certos casos, a mudar seus perfis ao encontrarem o filho real, abandonando a idealização. Deixa-se claro, entretanto, que:

Busca ativa não é esvaziar abrigos a qualquer preço, não é depositar crianças em lares que não as desejam, não é convencer pretendentes a se conformarem com a criança oferecida. Trata-se de apresentar possibilidades, de convidar a sociedade a conhecer crianças e abrigos com o olhar não preconceituoso, de dar a todos o direito à informação, ao diálogo, à mudança (KNOPMAN, 2014, p. 238).

A psicóloga esclarece que o contato pessoal com as crianças e adolescentes abrigados não permitia tratá-los como processos judiciais impessoais, uma vez que todos tinham nome e história e faziam pedidos diretos: "Tia, eu não quero ficar mais aqui no abrigo", "eu quero ir para casa”, "eu quero ir para sua casa”, "Eu quero uma família”. Para ela, eram apelos que exigiam respostas (KNOPMAN, 2014, p. 234).

Quando a abertura das instituições para que os candidatos habilitados da comarca conheçam os menores disponíveis à adoção não é suficiente, recorre-se à internet para a busca de candidatos a pais. Essa busca é feita através do WhatsApp, Facebook, do YouTube, do Instagram, assim como de aplicativos e sites específicos de adoção. Essa busca utiliza-se de imagens, vídeos e informações pessoais das crianças. Apesar da necessidade de habilitação do candidato no Cadastro Nacional da Adoção (CNA) para realizar a adoção, as informações dos menores ficam expostas a todos aqueles que tem acesso à internet, ampliando as possibilidades de encontrar pessoas interessadas em adotar.

A Busca Ativa na internet tem eficácia para encontrar pais para muitos menores.

É o caso de A. B., do Estado de Pernambuco, que conseguiu sua família por meio da página da Comissão Estadual Judiciária de Adoção de Pernambuco (CEJA-PE) no Facebook, a qual compartilhou a imagem de A.B., descrevendo-a como uma criança de 7 anos, meiga, mas que, em virtude de ter sofrido violência doméstica, havia ficado com sequelas motoras que envolviam a fala e a cognição. A criança, que nem andava, devido à ausência sofrida de amparo 
familiar, conseguiu encontrar pais que a acolhessem, dispostos inclusive a viajar quilômetros para buscá-la e passou a se desenvolver muito melhor na nova família. Em um outro caso, 4 irmãos foram adotados juntos após a Busca Ativa, o que demonstra que esse mecanismo pode favorecer a não separação de grupos de irmãos (CEJA-PE, 2019, online).

A Busca Ativa também é realizada em grupos específicos do Facebook $e$ WhatsApp, como o GAATE - Grupo Virtual de Apoio à Adoção Tardia e Especial e ATE Adoção Tardia e Especial, dentre outros. Ao contrário da página do CEJA-PE, feita pelo próprio poder judiciário, nessas encontra-se uma predominância de voluntários.

Uma outra forma de realização da Busca ativa acontece através de campanhas. A Comissão Estadual Judiciária da Adoção do Espírito Santo (CEJA/ES) tem a campanha “Esperando Por Você”, cujos vídeos podem ser acessados no próprio site ou no YouTube. Neles as crianças e adolescentes aparecem demonstrando seu desejo por uma família, e em muitos finalizam com a pergunta “quer ser minha família?". A campanha já encontrou pais a muitas crianças. Ao entrar no site já se tem acesso aos disponíveis como Alisson (17 anos) e Arli (16 anos), Breno (16 anos), Wanderson (16 anos), Jhenifer (10 anos) e Krauzemberg (12 anos $)^{8}$, dentre outras. Além do nome e da idade, pode-se assistir aos vídeos com os menores (TJES, 2019 , online).

Outra campanha que propicia muitas adoções é a "Adote um Pequeno Torcedor", promovida pela $2^{\mathrm{a}}$ Vara da Infância e Juventude, o time Sport Club do Recife e o Ministério Público de Pernambuco. Destaca-se a perspectiva do juiz envolvido:

Para o juiz titular da $2^{\text {a }}$ Vara da Infância e Juventude, Élio Braz, a campanha vem surpreendendo a toda a equipe do programa pela idade das crianças e adolescentes que estão sendo procurados para adoção. 'São meninos e meninas entre 10 e 17 anos de idade. Então, a iniciativa tem alcançado o objetivo que é quebrar os preconceitos e mitos da adoção tardia. Por meio da ação, as crianças e jovens colaboram de forma decisiva para o sucesso do programa, pois participam e protagonizam todo o processo de adoção e confirmam seus desejos de ter uma família e encontrar amor e proteção familiar', afirmou (TJPE, 2019, online).

Também podem ser citadas como bem sucedidas para a garantia da convivência familiar a muitas crianças a campanha "Adote um boa noite", do Tribunal de Justiça de São

\footnotetext{
${ }^{8}$ Nomes expostos pelo próprio Tribunal de Justiça do Espírito Santo no site.
} 
Paulo e a "Laços de Amor", da Assembleia Legislativa, do Ministério Público, da Ordem dos Advogados do Brasil e do Tribunal de Justiça de Santa Catarina.

O projeto “Adoção Tardia”, de iniciativa de voluntários, também proporciona a adoção de muitos antes rejeitados. Como é o caso de uma adolescente de 15 anos que aguardava adoção há dois anos e a divulgação do vídeo e posts em redes sociais despertaram o interesse em muitas famílias (URIARTT, 2019, online).

Observa-se que quando as crianças e adolescentes podem ser vistos e ouvidos pela sociedade, desmistificam-se os preconceitos e se enxerga que eles também podem ser filhos e merecem isso, concretizando-se adoções antes improváveis.

\section{CONCLUSÃO}

A convivência familiar é essencial para o desenvolvimento sadio de todos os menores. Ela possibilita vínculos ao indivíduo que as instituições de acolhimento não são capazes de propiciar, além de atenção individualizada necessária à formação da identidade. Em muitos casos as próprias crianças e adolescentes que estão institucionalizados verbalizam o desespero por uma família ou manifestam condutas que demonstram as consequências da ausência de uma família.

Apesar de a exposição de um menor solicitando por pais na internet não ser o ideal, pois pode trazer consequências negativas, é fato que esse mecanismo ajuda a desmitificar preconceitos e estigmas que envolvem a adoção. Por meio deles, as crianças e adolescentes cativam os pretendentes que decidem adotá-las.

A eficácia desse método excepcional de procura é indiscutível. Apesar de não garantir a todos uma nova família, possibilita um aumento grande das chances. Ressalta-se, entretanto, que a tentativa, a priori, poderia ser feita em um sistema mais restrito como o ADO.T - o qual somente pode entrar candidatos já cadastrados no CNA - e se frustrada, partiria-se para sistemas mais abertos, como o facebook e o Youtube, em que os vídeos, fotos e informações pessoais atingem milhares de pessoas indistintamente.

A convivência familiar possibilita a garantia de inúmeros direitos da personalidade, e por esse motivo é fundamental considerar a hipótese da utilização de imagens e informações pessoais das crianças e dos adolescentes se todos os outros mecanismos 
falharem. Evidencia-se, entretanto, a excepcionalidade da medida face à vulnerabilidade e às características psicológicas desses menores.

\section{REFERÊNCIAS}

ADOÇÃO BRASIL. Campanha Esperando Por Você. Disponível em: <http://www.adocaobrasil.com.br/campanha-de-adocao-esperando-por-voce/>. Acesso em: 19 de mar. 2019.

ADOT. A.DOT Uma nova chance. Disponível em: < https://adot.org.br/>. Acesso em: 19 de mar. 2019.

BITTAR, Carlos Alberto. Os Direitos da Personalidade. São Paulo: Saraiva, 2015.

BOCHNIA, Simone Franzoni. Da adoção - Categorias, Paradigmas e Práticas do Direito de Família. Curitiba: Juruá, 2010.

BRASIL. Constituição da República Federativa do Brasil de 1988. Brasília, DF: Presidência da República. $\quad$ Disponível em:< http://www.planalto.gov.br/ccivil_03/Constituicao/Constituicao.htm> . Acesso em: 1 mar. 2019.

. Lei $\mathrm{n}^{\text {o }}$ 8.069, de 13 de julho de 1990. Dispõe sobre o Estatuto da Criança e do Adolescente e dá outras providências. Brasília: Congresso Nacional, [1990]. Disponível em:< http://www.planalto.gov.br/ccivil_03/LEIS/L8069.htm>. Acesso em: 22 mar. 2019.

. Lei $\mathrm{n}^{\mathrm{o}}$ 10.406, de 10 de janeiro de 2002. Institui o Código Civil. Brasília:

Congresso Nacional, [2002]. Disponível em:<
http://www.planalto.gov.br/ccivil_03/LEIS/2002/L10406.htm>. Acesso em: 22 mar. 2019.

. Lei $\mathrm{n}^{\mathrm{o}} 12.010$, de 3 de agosto de 2009.

Congresso Nacional, [2009]. Disponível em:<

http://www.planalto.gov.br/ccivil_03/_Ato2007-2010/2009/Lei/L12010.htm>. Acesso em: 22 mar. 2019.

CANOTILHO, J. J. Gomes; MACHADO, Jónatas E. M. "Reality shows" e liberdade de programação. Coimbra: Ed. Coimbra, 2003.

CEJA-PE. PROJETO FAMíliA: Um direito de toda criança e adolescente. Disponível em: < https://www.facebook.com/cejapernambuco/?tn-str=k*F>. Acesso em: 19 de mar. 2019. 
CONSElHO NACIONAL DE JUSTIÇA. Cadastro Nacional de Adoção/ Relatório de Dados Estatístico. Disponível em:

http://www.cnj.jus.br/cnanovo/pages/publico/index.jsf/>. Acesso em 10 de abr. 2019.

. Tempo dos processos relacionados à adoção no Brasil - Uma análise sobre os impactos da atuação do poder judiciário. Brasília, 2015. Disponível em:<http://www.cnj.jus.br/files/conteudo/destaques/arquivo/2015/07/8aab4515becd0379339 60ba8e91e1efc.pdf $>$. Acesso em: 10 de abr. 2019.

CORDEIRO, António Menezes. Tratado de Direito Civil português. Coimbra: Almedina, 2004.

CUNEO, Mônica Rodrigues. ABRIGAMENTO PROLONGADO: OS FILHOS DO ESQUECIMENTO. In: A Institucionalização Prolongada de Crianças e as Marcas que Ficam. Censo da população infanto-juvenil abrigada no Estado do Rio de Janeiro. Rio de Janeiro: 2012.

DIAS, Maria Berenice. Filhos do Afeto - Questões Jurídicas. $2^{\text {a }}$ Ed. São Paulo: Editora Revista dos Tribunais, 2017.

FREIRE, Fernando (Org.). Abandono e Adoção. Curitiba: Terre des hommes, 1994, p.7.

KNOPMAN, Eliana Bayer. Busca Ativa na Adoção: Quando a Espera Passiva é Violação de Direitos. In: LADVOCAT, Cynthia et al. Guia de Adoção: No Jurídico, no Social, no Psicológico e na Família. São Paulo: Roca, 2014. Cap. 17. p. 231-239.

LUCHI, Tânia O. Construção do Vínculo na Adoção Tardia: Fatores Interatuantes. In: LADVOCAT, Cynthia et al. Guia de Adoção: No Jurídico, no Social, no Psicológico e na Família. São Paulo: Roca, 2014. Cap. 54. p. 647-656.

MELlO, Anna Christina da Motta Pacheco Cardoso de. 101 Perguntas e Respostas sobre Alternativas de Convivência Familiar - Família de Apoio, Guarda e Apadrinhamento Afetivo. São Paulo: CECIF, 2003.

PODER JUDICIÁRIO DE PERNAMBUCO. Projeto Família - Busca Ativa. Disponível em: < http://www.tjpe.jus.br/web/infancia-e-juventude/adocao/busca-ativa>. Acesso em: 19 de mar. 2019.

. Projeto “Adote um Pequeno Torcedor” estimula adoção tardia. Disponível em: < http://www.tjpe.jus.br/-/projeto-adote-um-pequeno-torcedor-estimula-adocao-tardia>. Acesso em: 19 de mar. 2019. 
PORTAL DA ADOÇÃO. O que é Busca Ativa. Disponível em: $<$ http://portaldaadocao.com.br/artigos/a-palavra-do-especialista/23-o-que-\%C3\%A9-buscaativa\&gt>. Acesso em: 19 de mar. 2019.

SCHREINER, Gabriela. Por uma cultura da Adoção para a criança? São Paulo: Editora Consciência Social, 2004.

SPORT CLUB DO RECIFE. Adote um pequeno torcedor. Disponível em: <https://www.adoteumpequenotorcedor.com/>. Acesso em: 29 mar. 2019.

TRIBUNAL DE JUSTIÇA ESPÍRITO SANTO. Campanha Esperando por Você. Disponível em: <https://www.youtube.com/watch?v=q3I0kf2xHtc\&amp;list=PLhso79RkLvaoNUZoVONGn zJiLVRVsUMsN\&gt>. Acesso em: 19 de mar. 2019.

Crianças e adolescentes disponíveis para adoção. Disponível em: < http://www.tjes.jus.br/esperandoporvoce/criancas-e-adolescentes-disponiveis-paraadocao/arli-15-anos-alisson-16-anos-e-alikis-17-anos/>. Acesso em: 19 de mar. 2019.

URIARTT, Simone et al. Projeto "Adoção Tardia". Disponível em: <www.adocaotardia.com>. Acesso em: 16 de mar. 2019.

VARGAS, Marlizete Maldonado. Adoção tardia: da família sonhada à família possível. São Paulo: Casa do Psicólogo, 1998. 